\title{
Diferencial de ganhos entre migrantes e não migrantes em Minas Gerais
}

\author{
Luiz Carlos Day Gama* \\ Ana Maria Hermeto**
}

\begin{abstract}
Este estudo analisa as causas dos diferenciais de rendimentos entre migrantes e não migrantes no estado de Minas Gerais. Sob a hipótese de que os diferenciais e suas causas se distinguem ao longo da distribuição de ganhos, são estimadas regressões quantílicas e, com os resultados destas estimativas, realizadas decomposições de diferenças, pelo método de Junh, Murphy e Pierce (JMP). Os resultados indicam que: existe desigualdade de rendimentos em favor dos migrantes, tendo crescido entre 2000 e 2010; como esperado, diferencias são explicados de forma diferenciada em cada quantil da distribuição de rendimentos; efeitos não observados (produtividade, esforço, etc.) são importantes para explicar as desigualdades, em ambos os anos; entretanto, para explicar o crescimento da divergência de rendimentos entre migrantes e não migrantes, as características observáveis e não observáveis são mais importantes do que os retornos em si de tais características. Conclui-se, dessa forma, como defende grande parte da literatura, que os migrantes realmente são positivamente selecionados, porém, entre aqueles com maior nível de educação formal, principalmente em 2010, não é possível adquirir o rendimento esperado, ou a diferença de rendimento esperada, dadas suas maiores habilidades.
\end{abstract}

Palavras-chave: Migrantes. Minas Gerais. Decomposição de diferenças. Desigualdade de rendimentos.

\footnotetext{
* Universidade Federal de Minas Gerais (UFMG), Belo Horizonte-MG, Brasil (Icdgama@gmail.com).

${ }^{\star *}$ Universidade Federal de Minas Gerais (UFMG), Belo Horizonte-MG, Brasil (ahermeto@cedeplar.ufmg.br).
} 


\section{Introdução}

Diferenciais de rendimentos entre migrantes e não migrantes representam um fenômeno que ocorre no Brasil, e o estado de Minas Gerais não foge à regra. As profundas transformações pelas quais o Brasil passou nos últimos anos - especialmente a queda na desigualdade de renda - podem ter modificado o processo migratório e também os retornos às escolhas dos trabalhadores, dado que, como argumenta Soares (2010), a renda do trabalho tenha sido mais importante para redução da desigualdade do que a renda de transferências (IPEA, 2006; SOARES, 2010). Utilizando como indicador o índice de Gini, verifica-se que, em 2001, seu valor era de 0,592, passando para 0,538, em 2009. Dessa forma, esse trabalho objetiva analisar como se encontram os diferenciais de rendimentos entre migrantes e não migrantes, dadas estas modificações. Nesse contexto, a migração é entendida no presente trabalho como uma decisão familiar e relacionada a motivos econômicos, da forma como é abordada por Borjas (2004).

A escolha de Minas Gerais como unidade de análise deve-se a alguns fatores. Nos últimos anos, segundo dados do Censo Demográfico de 2000 e 2010, o estado de Minas Gerais foi o que menos cresceu, em termos populacionais, na região Sudeste. Um dos motivos é a queda do fluxo de entrada dos migrantes, como será visto adiante. Isso pode ser um sinal de que Minas Gerais tornou-se um estado menos atrativo comparativamente a outros.

Além disso, a composição espacial de Minas Gerais, que reflete grandes disparidades em todos os aspectos sociais, em termos tanto da distribuição no espaço quanto da caracterização da hierarquia dos municípios (pequenos, médios, grandes), torna ilustrativo o estudo da migração no estado.

Para a consecução dos objetivos, primeiramente, são estimadas regressões quantílicas para os percentis 10, 25, 50, 75 e 90. A partir destas estimativas, é aplicada uma metodologia de análise contrafactual para cada quantil: a decomposição de Junh, Murphy e Pierce (1993). Como aponta Ulyssea (2007), trata-se de um método paramétrico, em que se é possível obter distribuições contrafactuais, que permitem decompor a desigualdade de rendimentos nos chamados efeitos-preço, efeitos-quantidade e efeitos não observáveis. Aqui, o diferencial de rendimentos não explicado não é entendido como resultado de uma discriminação no mercado de trabalho, mas sim de habilidades não observadas.

0 intuito é obter distribuições contrafactuais dos rendimentos que permitam identificar a contribuição de determinados fatores para os diferenciais de rendimentos entre migrantes e não migrantes. A questão a ser respondida é: os efeitos não observados contribuem para o aumento do diferencial de rendimentos ou para uma queda?

Os resultados mostram que habilidades não observadas são importantes para explicar diferenciais de rendimentos e seus efeitos se distinguem quando são comparados diferentes percentis. Porém, os retornos às habilidades são superiores entre os nativos, pensando em termos de mudanças ao longo do período. 
A seguir apresenta-se a revisão da literatura com alguns fatos estilizados. Posteriormente é abordada a metodologia utilizada para a análise que o artigo propõe e discutem-se os resultados. Por fim, são tecidas as considerações finais.

\section{Revisão da literatura sobre migração}

Em geral, a literatura sobre o tema aponta diversos impactos da migração sobre o mercado de trabalho no local de destino, seja nas taxas de desemprego (CARD, 2005), seja em relação aos salários (BORJAS, 1985, 1995), por meio do aumento da competição no local de destino. É importante também entender o perfil destes migrantes e a razão que guia os mesmos para a decisão de migrar.

Em um dos estudos pioneiros sobre migração, Sjaastad (1962) afirma que um trabaIhador ao migrar enfrenta custos monetários e não monetários. 0 autor percebe o processo migratório do mesmo modo que formação educacional, ou seja, um investimento por parte do indivíduo. Sabe-se que, quanto maior for o salário auferido por um trabalhador em uma dada localidade, menor será a probabilidade de que ele saia do seu emprego e migre para outra região. Porém, quanto maior for a renda total do trabalhador, mais condições ele terá para financiar sua migração, podendo assim aumentar a probabilidade de que ele migre (PEREIRA, 2000).

Basker (2003), analisando a migração interna nos Estados Unidos, concluiu que a mobilidade é relacionada positivamente com a educação e negativamente com a idade, ou seja, quanto mais qualificado for o indivíduo, maior é a probabilidade de sua migração e, quanto mais velho, menores são as chances. Borjas (1987) e Dustmann e Glitz (2011) argumentam que os migrantes são positivamente selecionados com relação às características não mensuráveis, ou seja, apresentam uma propensão maior a migrar e, em média, melhores características não observáveis ${ }^{1}$ do que os não migrantes, podendo, assim, arcar com os custos de migrar e contribuindo para um aumento de produtividade no local de destino e uma redução no de origem. Logo, é provável que as regiões receptoras dos migrantes fiquem em melhores condições, pois a migração estaria contribuindo para um aumento da divergência de renda, já que estas regiões são as mais ricas. Freguglia (2007) também segue essa linha e afirma que os migrantes não constituem uma amostra aleatória da população nas localidades de origem e aumentos salariais após a migração podem estar refletindo habilidades não observadas que os tornam mais produtivos. 0 impacto sobre a região de destino dependeria, assim, dos diferencias de habilidades entre os migrantes e os não migrantes.

Entre possíveis impactos, a queda do salário dos nativos é apontada por parte literatura (CARD, 2001a; BORJAS, 2003; AMARAL; RIOS-NETO; POTTER, 2016) como consequência da maior oferta de trabalho na região. Entretanto, Card (2001b) e Lewis (2003) não encontraram

\footnotetext{
${ }^{1}$ Como exemplos de características não observáveis, podemos destacar as habilidades e a produtividade de um indivíduo.
} 
impactos expressivos da entrada de imigrantes em determinada localidade quando são considerados os salários de nativos de baixa educação formal.

Nem todos os trabalhos indicam a seleção positiva dos migrantes. Axelsson e Westerlund (1998), ao analisarem o efeito da migração sobre os rendimentos de famílias suecas, utilizando dados em painel para o período 1980-1990, observaram que a migração não exerce impacto significativo sobre os rendimentos. Além disso, os autores não rejeitam a hipótese de não existência de autosseleção dos migrantes e fazem uma crítica aos estudos sobre autosseleção dos migrantes que consideram apenas um membro da família na análise. Eles contribuem para a literatura incluindo a renda de toda a família. Borjas (2004) afirma que a migração é sempre guiada pelos mesmos motivos: trabalhadores almejam melhorar suas condições econômicas e as empresas querem contratar trabalhadores com maior qualificação. Ainda, segundo o autor, dado que a migração é tratada como um investimento em capital humano, é de se esperar que os indivíduos mais jovens sejam mais propensos a migrar, uma vez que possuem maior tempo para recuperar o investimento, e, também, sejam mais educados, pois pessoas com maior qualificação observam de maneira mais correta as oportunidades em outras regiões e, dessa forma, o custo de migrar é reduzido.

A teoria neoclássica diz que, quando em uma região a oferta de mão de obra é elevada e o capital é escasso, os indivíduos tendem a tomar a decisão individual de migrar para regiões em que a demanda por trabalho esteja elevada e o capital seja abundante. Dessa forma, os diferenciais de salários são considerados na literatura econômica tradicional o principal fator que leva um trabalhador a migrar. É de se esperar que os trabalhadores migrem de regiões onde os salários são menos elevados para outras onde são mais altos. Há no mercado de trabalho brasileiro muitos diferenciais salariais não explicados, ocorrendo diferenciais inclusive para indivíduos com mesma qualificação.

Entretanto, Segundo Sasaki e Assis (2000), algumas pesquisas têm desafiado suposições e conclusões da teoria neoclássica, tais como a de que a decisão de um indivíduo migrar não seria individual, mas sim em conjunto, em família, não estando relacionada apenas a fatores pecuniários. Nesse trabalho assume-se que a decisão é familiar e, por isso, como será visto adiante, variáveis relacionadas às características familiares são utilizadas como controles nas estimativas.

Com relação à literatura nacional, Santos e Ferreira (2007), empregando dados das PNADs de 1999 e 2003, testaram a hipótese de que os migrantes são positivamente selecionados. Primeiramente, os autores estimaram uma equação minceriana para o logaritmo do salário e, posteriormente, construíram contrafactuais para analisar a renda no Brasil com e sem os migrantes. Os resultados encontrados apontam que a renda média no Brasil diminui quando são excluídos os migrantes ${ }^{2}$ e os estados que recebem os migrantes apresentam aumentos na renda média, com exceção do Espírito Santo e de São Paulo. Gama e Machado

\footnotetext{
2 É consenso considerar na análise apenas indivíduos entre 20 e 70 anos, ou intervalos próximos deste, pois deseja-se captar apenas aqueles que migraram por motivos econômicos.
} 
(2014), a partir de dados dos Censos 2000 e 2010, também encontraram evidências que apontam que os migrantes são positivamente selecionados no Brasil.

Batista e Cacciamali (2009), analisando o diferencial de ganhos por gênero em um contexto de migração, mostram, por intermédio dos dados da PNAD de 2005, que os migrantes ganham mais do que os não migrantes para ambos os sexos, sendo o diferencial de ganhos por gênero maior para os migrantes em comparação aos não migrantes, o que corrobora a hipótese de que as mulheres são negativamente selecionadas em relação aos homens, quando decidem migrar. Os homens se encontram em melhor situação do que as mulheres em todas as parcelas da decomposição: características específicas, atributos e valoração do mercado. Por fim, além de a participação feminina no mercado de trabalho estar aumentando, o percentual de migrantes do sexo feminino também vem crescendo em todo mundo (HOLST et al., 2008).

Com relação a trabalhos que comparam ganhos de migrantes e nativos, diferentes abordagens são encontradas na literatura. Dell'Aringa, Lucifora e Pagani (2015), utilizando dados do mercado de trabalho italiano, verificaram que retornos ao capital humano são consideravelmente menores entre os imigrantes em comparação aos nativos. Além disso, capital humano não contribui para que os imigrantes tenham acesso a ocupações mais bem remuneradas.

Analisando diferenciais a partir da decomposição dos salários, Nanos e Schluter (2013), por meio da aplicação de um modelo de equilíbrio geral de procura "on the job", decompõem os salários em várias partes e analisam o que os autores chamam de "efeito migração". Esse efeito é definido como a diferença de ofertas de emprego entre nativos e migrantes pertencentes ao mesmo segmento de trabalho, com idades similares e empresas com produtividades similares. 0 intuito no presente estudo é o mesmo, ou seja, analisar as causas dos diferenciais de rendimentos. Entretanto, aplica-se metodologia completamente distinta à do trabalho citado.

Além do já mencionado nessa seção, várias outras características individuais e familiares interferem na decisão de um indivíduo migrar, tais como renda, educação, número de filhos, etc. É importante que se considerem tais atributos na mensuração dos diferencias de rendimentos entre os grupos a serem analisados.

\section{Aspectos metodológicos}

\section{Regressão quantílica}

Regressões quantílicas são utilizadas para avaliar como os quantis de uma variável dependente, aqui o logaritmo do rendimento mensal, mudam em resposta a um conjunto de variáveis independentes. Em outras palavras, permitem analisar o impacto das variáveis explicativas nos diferentes pontos da distribuição condicional da variável dependente, o que possibilita explorar uma maior quantidade de informações presentes nos dados, 
importantes em situações em que o comportamento médio é pouco representativo, diferentemente da regressão de mínimos quadrados ordinários (MQO), que estima apenas o efeito médio do impacto de uma variável na distribuição condicional de outra variável dependente. Dessa forma, regressões quantílicas são mais robustas em resposta à presença de outliers.

Esta técnica foi introduzida por Koenker e Basset (1978). Considera-se $\left(y_{i} x_{i}\right), i=1, \ldots, n$ uma amostra de uma população qualquer, onde $x_{i}$ é um vetor de $(\mathrm{Kx} 1)$ variáveis explicativas e $y_{i}$ é a variável dependente. 0 $\theta$-ésimo quantil de $y$ é definido como:

$F^{-1}=\inf \{y: F(y) \geq \theta\}$

Onde $F$ é a função de distribuição (não condicionada) de $y$. Para o caso de uma relação linear entre $y$ e $x$, temos:

$y_{i}=x_{i}^{\prime} \beta+\mu_{i}$

Onde $\beta$ é um vetor de parâmetros. Dessa forma, têm-se os quantis condicionais da distribuição de $y$ definidos a partir dos quantis da distribuição dos erros:

$\operatorname{Pr}\left(y_{i} \leq y / x_{i}\right)=F_{\mu \theta}\left(y-\frac{x_{i}^{\prime} \beta_{\theta}}{x_{i}}\right), i=1, \ldots . n$.

A partir da equação (3) define-se a função quantílica por:

$Q_{\theta}\left(y_{i} / x_{i}\right)=x^{\prime}{ }_{i} \beta_{\theta}+\mathrm{F}_{\mu}^{-1}(\theta)$

$\mathrm{Na}$ regressão quantílica, os quantis devem ser analisados como incondicionais, como a solução de um problema de maximização. Assim, o estimador $\beta_{\theta}$ da regressão quantílica (equação 4) é definido com a solução da seguinte função objetivo:

$\min \frac{1}{n} \sum_{i: y_{i} \geq x_{i} \beta} \theta\left|y_{i}-x_{i} \beta\right|+\sum_{i: y_{i} \geq x_{i} \beta} 1-\theta\left|y_{i}-x_{i} \beta\right|=\min \frac{1}{\beta} \sum_{i=1}^{n} \rho_{\theta}\left(y_{i}-x_{i} \beta\right)$

É válido ressaltar que, diferentemente do método de mínimos quadrados ordinários (MQO), aqui há minimização de valores absolutos. 0 modelo especifica a função quantil condicional da variável dependente $y$, dada a matriz de regressores $X$ como:

$Q_{y}(\theta / X)=X \beta(\theta)$, onde $\theta=[0,1]$

Como argumenta Buchinsky (1998), a regressão quantílica apresenta características que a tornam extremamente interessante:

- os modelos podem ser usados para caracterizar toda a distribuição condicional de uma variável resposta dado um conjunto de regressores;

- a função objetivo da regressão quantílica é uma soma ponderada de desvios absolutos, fornecendo uma medida de locação robusta, de modo que o vetor de coeficientes estimado não é sensível a observações extremas na variável dependente;

- quando os erros não seguem a distribuição normal, os estimadores de regressão quantílica podem ser mais eficientes do que aqueles de mínimos quadrados;

- soluções diferentes para quantis distintos podem ser interpretadas como diferenças na resposta da variável dependente às mudanças nos regressores em vários pontos da distribuição condicional da variável dependente. 
No caso de estimação de diferencial de salários, a regressão quantílica é uma ferramenta interessante, pois permite a análise intragrupo da desigualdade de salários, medida pela diferença entre quantis condicionais (BUCHINSKY, 1994). Portanto, é possível, por exemplo, analisar o efeito de determinada característica, como educação, sobre rendimentos de indivíduos em diferentes pontos da distribuição de ganhos. Pode-se responder, por exemplo, se o efeito da escolaridade sobre os rendimentos é o mesmo para os $10 \%$ mais pobres e os $10 \%$ mais ricos.

No presente trabalho, a mesma regressão é estimada para os percentis 10, 25, 50, 75 e 90, para avaliar o comportamento dos diferenciais de rendimento entre migrantes e não migrantes ao longo dos diferentes percentis da distribuição dos rendimentos.

\section{Decomposição de Juhn, Murphy e Pierce (JMP)}

A decomposição de Oaxaca-Blinder consiste em um método que explica diferenciais de rendimentos em características individuais (efeitos de características), diferenças nos coeficientes das equações de salários (efeitos de coeficientes) e diferenças nos resíduos (efeitos de resíduos). Tal método vem sendo amplamente utilizado para o entendimento de diferencias de salários por gênero e raça, em que os efeitos de coeficientes são usualmente interpretados como medidas de discriminação (YUN, 2009). No presente trabalho, como a hipótese é a de que efeitos não observáveis afetam a diferença de ganhos entre migrantes e não migrantes, a decomposição de Oaxaca não é a melhor ferramenta, pois não permite separar o efeito “discriminação” do efeito de características não observáveis.

Juhn, Murphy e Pierce (1993) ampliaram a decomposição de Oaxaca-Blinder para outras características da distribuição, sendo possível, nesse caso, verificar o efeito de habilidades não observáveis sobre o diferencial de ganhos entre migrantes e não migrantes. Tal metodologia, conhecida como decomposição de Juhn, Murphy e Pierce (JMP), é utilizada para decompor diferenciais de rendimentos e enfatiza o papel de mudanças na distribuição relativa de cada grupo, adotando como hipótese a divergência salarial. Além disso, pode-se operacionalizá-la ao longo dos quantis de uma distribuição e entre medidas de desigualdade, incorporando à decomposição o termo de erro, que supostamente é nulo na média, mas diferente de zero nos quantis (RODRIGUES, 2009).

A decomposição de JMP será aplicada aos resultados das estimativas das regressões quantílicas. Em outras palavras, para cada percentil analisado (10, 25, 50, 75 e 90) será aplicada uma decomposição pelo método em questão, entre migrantes e não migrantes. A seguir, a formalização do método é sumariamente descrita, baseada em Juhn, Murphy e Pierce (1993). Como afirmado anteriormente, o intuito é comparar os rendimentos do grupo migrantes $(M)$ com os rendimentos dos nativos $(N)$. Pode-se representar a equação da seguinte maneira:

$Y_{i}=X_{i} \beta_{k}+u_{i}$ 
Onde $Y_{i t}$ é o logaritmo do rendimento do indivíduo pertencente ao grupo $i$ (pode ser $\mathrm{M}$ ou N), $X_{i t}$ é um vetor de características individuais e $u_{i}$ é o componente do erro não explicado. Seguindo a decomposição de Oaxaca, pode-se decompor a média de diferencias de rendimentos entre os grupos $\mathrm{M}$ e $\mathrm{N}$ da seguinte forma, como apresentado em Yun (2009): $\bar{Y}_{M}-\bar{Y}_{N}=\left(\bar{X}_{M}-\bar{X}_{N}\right) \beta_{M}+\bar{X}_{N}\left(\beta_{M}-\beta_{N}\right)+\left(\bar{\varepsilon}_{M}-\bar{\varepsilon}_{N}\right)$

Onde os três componentes representam, respectivamente: os efeitos de características, denominados de efeitos-quantidade, que são relacionados às características produtivas dos trabalhadores, como educação e experiência; os efeitos de coeficientes, chamados de efeitos-preço, que medem os retornos às características observáveis; e os efeitos de resíduos, que captam a parcela atribuída a fatores não observáveis que afetam a remuneração.

Se o intuito é captar as habilidades não observadas, a equação (7) não pode ser estimada via mínimos quadrados ordinários (MQO), pois assume-se que $\bar{\varepsilon}_{i}=0$. Logo, a decomposição de JMP possibilita analisar as habilidades não observadas mesmo que o método MQO seja aplicado.

Os autores assumem que o retorno às características individuais é o mesmo para ambos os grupos $\mathrm{M}$ e N $\left(\beta_{M}=\beta_{N}\right)$ e constrói-se uma função de rendimentos auxiliar para o grupo $\mathrm{N}$ : $Y_{N}=X_{M} \beta_{M}+U_{N}$

Utilizando esta função de rendimentos auxiliar para o grupo N, o método JMP propõe a seguinte equação de decomposição:

$\bar{Y}_{M}-\bar{Y}_{N}=\left(\bar{X}_{M}-\bar{X}_{N}\right) \beta_{M}-\bar{U}_{N}=\left(\bar{X}_{M}-\bar{X}_{N}\right) \beta_{M}-\bar{\theta}_{B}^{*} \sigma_{M}$

Onde $\sigma_{M}$ é o desvio padrão do resíduo $\left(\varepsilon_{M}\right)$ e $\bar{\theta}_{B}^{*}=\bar{U}_{N} / \sigma_{M}$.

0 primeiro e segundo termos do lado direito da equação (10) representam os diferenciais predito e residual, respectivamente. Assume-se que o diferencial residual é relacionado com a distribuição de habilidades não observáveis, sendo idêntico ao efeito de coeficientes do modelo de Oaxaca, se o método MQO é usado.

A decomposição supracitada pode ser estendida de forma a captar mudanças ao longo do tempo. Baseando-se na equação (10) para um único período, as mudanças nos diferencias de salários, de acordo com Yun (2009), podem ser expressadas da seguinte forma:

$D_{s}-D_{t}=\left(\Delta X_{s}-\Delta X_{T}\right) \beta_{A t}+\Delta X_{s}\left(\beta_{A s}-\beta_{A t}\right)+\left(\Delta \theta_{s}^{*}-\Delta \theta_{t}^{*}\right) \sigma_{A t}+\Delta \theta_{s}^{*}\left(\sigma_{A s}-\sigma_{A t}\right)$

Onde os subscritos $s$ e $t$ representam distintos pontos no tempo e a diferença $D_{S}-D_{t}$ corresponde à diferença total, um termo que pode indicar convergência ou divergência dos salários ao longo do tempo.

Como mostram os dois últimos termos da equação (11), o método JMP considera mudanças na parte não explicada, em termos de mudanças em preços e quantidades, como fontes de mudanças nos diferenciais de salários. Juhn, Murphy e Pierce (1993) argumentam que estas mudanças podem capturar modificações em habilidades não observadas ou de discriminação, porém o primeiro é o mais provável. 
Apesar de ser amplamente utilizado na literatura, esse método apresenta limitações. Suen (1997) e Fortin, Lemieux e Firpo (2011) argumentam que a hipótese de que os resíduos computados para cada trabalhador são independentes das variáveis explicativas é forte e, nas palavras dos autores, não realista. Dessa forma, o correto seria decidir como condicionar em $X$ quando implementar o procedimento de imputação, como faz, por exemplo, Machado e Mata (2005). Os autores propõem um método distinto que se baseia na estimação da função de densidade marginal dos salários em um período, implicada pelas distribuições contrafactuais de alguns ou de todos os atributos observados.

Entretanto, a modelagem empregada no presente trabalho tem a vantagem de separar o efeito intragrupo do efeito entre grupos, permitindo satisfatoriamente captar o quanto a desigualdade intragrupos contribui para a própria desigualdade entre grupos, o que a torna suficiente para a aplicação no presente trabalho. Em outras palavras, dada a questão temporal, é possível analisar em que medida um crescimento ou queda do diferencial de rendimentos entre migrantes e nativos pode ser explicado pela parte residual ou por características observadas. No modelo de Machado e Mata (2005) isso não é possível, pois mudanças em habilidades não observadas refletem em mudanças dos coeficientes.

\section{Dados}

Para a estimativa dos modelos propostos, foram utilizados dados dos Censos Demográficos 2000 e 2010. O Censo é realizado pelo Instituto Brasileiro de Geografia e Estatística (IBGE) e ocorre a cada dez anos. O período de coleta do Censo 2010 foi de $1^{\text {o }}$ de agosto a 31 de outubro de 2010. No total, foram recenseadas 185.712 .713 pessoas em todo o território nacional. Já para o Censo de 2000, o período de coleta teve início em 1 을 de agosto de 2000 e terminou em 30 de novembro do mesmo ano. Neste trabalho, os dados são restringidos para o estado de Minas Gerais.

Para uma estimativa correta do diferencial de rendimentos entre migrantes e não migrantes, é necessária uma seleção na amostra, ou seja, precisa-se de alguns filtros nos dados. Em primeiro lugar, a amostra selecionada é composta apenas por indivíduos com idade entre 25 e 65 anos, pois o intuito é captar aqueles que decidem migrar por motivos econômicos. Indivíduos jovens muitas vezes não optam por migrar, mas fazem parte de uma decisão tomada pelo chefe do domicílio, além do fato de não terem tido a chance de completar o ensino superior, variável importante para determinar diferencias de rendimentos. Já as pessoas com mais de 65 anos dificilmente migram pensando em possibilidades de emprego na região de destino.

As variáveis relacionadas à renda, em 2000, foram deflacionadas pelo Índice Nacional de Preços ao Consumidor (INPC) para os patamares de julho de 2010. Indivíduos com rendimento no trabalho principal acima de $\mathrm{R} \$ 300.000,00$ foram excluídos da amostra, pois, por se tratar de outliers, podem elevar a média de um determinado grupo, acarretando conclusões incorretas. Obviamente, por se tratar de um estudo que analisa diferenciais de rendimentos, foram incluídos apenas aqueles com rendimentos positivos. A variável 
cor também passou por filtragem, sendo que amarelos, indígenas e indivíduos que não declaram nenhuma cor foram excluídos, pois eram pouco representativos. Também não foram considerados os indivíduos cujo nível de instrução era indeterminado.

Para a criação da dummy de migração, é necessário decidir qual conceito de migrante pretende-se utilizar. Primeiramente, são consideradas tanto as migrações intraestaduais quanto as interestaduais. Ademais, opta-se por empregar a classificação em que migrantes são aqueles indivíduos que realizaram o movimento nos últimos cinco anos, ou seja, pelo quesito de data-fixa. Portanto, não migrantes são as pessoas que residem no mesmo município há pelo menos cinco anos, independentemente se nasceram ou não em tal cidade. Além disso, três tipos de migrantes podem ser considerados: migrantes de única etapa (realizaram apenas um movimento e viviam em uma localidade diferente em 1995 e 2000, para os dados de 2000; viviam em uma localidade diferente em 2000 e 2010, para os dados de 2010), migrantes progressivos (realizaram mais de um movimento no período de cinco anos e moravam em localidade diferente da origem do primeiro movimento); e migrantes de retorno (viviam na mesma localidade em 1995 e 2000, 2005 e 2010 para os dados de 2000 e 2010, respectivamente, porém realizaram um movimento no período). Em trabalho recente, com as mesmas bases, Gama (2014) encontrou evidências de que migrantes de única etapa e os de retorno recebem melhores rendimentos do que os não migrantes e são positivamente selecionados com relação às características observadas e não observadas. Porém, o autor também verificou que, apesar dos maiores rendimentos, muitos destes migrantes retornam para sua localidade, pois almejam corrigir um erro, que foi o primeiro movimento. Logo, eles se assemelham mais a nativos do que aos migrantes, dado o curto espaço de tempo. Portanto, para o entendimento do diferencial de ganho entre migrantes e não migrantes, e dadas as hipóteses já mencionadas, na nossa análise foram considerados apenas migrantes de única etapa e progressivos, sendo excluídos os de retorno.

Na literatura sobre migração internacional assume-se, geralmente, que os migrantes necessitam de um tempo de assimilação (BORJAS, 1985, 1995), devido a questões de aprendizado do idioma, adaptação ao mercado de trabalho, etc. Com relação à migração interna, espera-se que a assimilação seja mais rápida e em pouco tempo os migrantes podem apresentar características similares aos nativos, o que justificaria a escolha pelo critério de data fixa. É possível argumentar que o tempo de assimilação pode influenciar nos diferenciais de rendimentos. Nesse caso, como não é controlado, tal efeito faria parte do diferencial residual.

Com isso, as amostras de 2000 e 2010 são compostas, respectivamente, por 842.530 e 803.534 indivíduos. As variáveis utilizadas como controle são: dummy de sexo (igual a 1 se for feminino e 0 se for masculino); dummy de cor (igual a 1 para brancos e 0 para não brancos - pardos e pretos); categórica que define nível de instrução (sem instrução e fundamental incompleto; fundamental completo e médio incompleto; médio completo e superior incompleto; e superior completo); idade; idade ao quadrado; status conjugal (vive com cônjuge; não vive, mas já viveu; e nunca viveu); categórica que define posição 
na ocupação (trabalhador doméstico com carteira de trabalho assinada; trabalhador doméstico sem carteira de trabalho assinada; empregado com carteira de trabalho assinada; empregado sem carteira de trabalho assinada; empregador; e conta-própria); dummy que assume o valor 1 se o indivíduo reside em área metropolitana e 0 se não reside; e uma dummy com valor 1 se o trabalhador reside em área rural e 0 se não reside.

\section{Resultados}

Para a obtenção das estimativas são utilizados os microdados da amostra dos Censos de 2000 e 2010. Primeiramente, apresentam-se as estatísticas descritivas e, posteriormente, as estimativas via regressões quantílicas. Por fim, são expostos os resultados paras as estimativas por decomposição de diferenças.

\section{Estatísticas descritivas}

Em 2000, como pode ser observado na Tabela 1, em torno de $10 \%$ da amostra é composta por migrantes, $55,4 \%$ de brancos, $36,9 \%$ de mulheres, $20,5 \%$ com ensino médio completo ou superior incompleto, $7,2 \%$ com ensino superior completo, $36,2 \%$ vivendo em alguma das regiões metropolitanas de Minas Gerais, $14,9 \%$ residindo em áreas rurais e $48,7 \%$ dos trabalhadores entre 25 e 65 anos casados. Analisando as informações da mesma tabela, percebe-se a ocorrência de algumas mudanças dez anos depois, para os dados do Censo 2010. 0 percentual de migrantes diminuiu consideravelmente, podendo ser resultado de dois fenômenos: uma queda geral dos movimentos migratórios no Brasil, como aponta Gama (2014); ou o efeito de uma menor atratividade de Minas Gerais em relação a outros estados. Estas questões não são abordadas no presente trabalho.

TABELA 1

Distribuição da amostra utilizada, segundo variáveis

Estado de Minas Gerais - 2000-2010

\begin{tabular}{|c|c|c|}
\hline & & \\
\hline Variáveis & 2000 & 2010 \\
\hline Migrantes & 10,03 & 7,41 \\
\hline Brancos & 55,4 & 47,96 \\
\hline Mulheres & 36,92 & 41,73 \\
\hline Ensino médio & 20,48 & 26,98 \\
\hline Ensino superior & 7,22 & 14,43 \\
\hline Vive com cônjuge & 57,47 & 67,30 \\
\hline Renda do trabalho (média em reais) & 936,44 & $1.318,11$ \\
\hline Reside na Região Metropolitana & 31,62 & 33,72 \\
\hline Reside em área rural & 14,94 & 11,14 \\
\hline
\end{tabular}

Fonte: IBGE. Censo Demográfico 2000 e 2010. Elaboração dos autores.

Com relação às outras variáveis, a Tabela 1 mostra que houve aumento da participação de pretos e pardos na população ocupada, sendo que os brancos deixaram de ser maioria e passaram a registrar uma participação de aproximadamente $48 \%$. As mulheres também 
ganharam espaço no período, sendo em 2010 responsáveis por $41,7 \%$ da população ocupada, ganho de aproximadamente 5 pontos percentuais. A educação também apresentou melhora no período, sendo que o percentual daqueles com ensino superior dobrou entre 2000 e 2010. A proporção de indivíduos vivendo com cônjuges cresceu no período. Com relação à renda do trabalho, observa-se um crescimento real considerável no período, em torno de $41 \%$. Por fim, houve aumento do percentual de trabalhadores residindo em áreas urbanas e redução para aqueles vivendo em áreas rurais.

Grande parte da literatura defende que os migrantes são positivamente selecionados e, por isso, são mais bem remunerados do que os não migrantes. A comparação de rendimentos e escolaridade entre migrantes e não migrantes é apresentada na Tabela 2, que também traz dados por cor e gênero, dada a discriminação no mercado de trabalho brasileiro, já amplamente debatida pela literatura.

Observa-se que os rendimentos do trabalho percebidos por migrantes são, em média, maiores do que os dos não migrantes, sendo que essa diferença apresentou crescimento expressivo, passando de aproximadamente $10 \%$ para cerca de 26,5\%, entre 2000 e 2010 . Em outras palavras, ambos os grupos ganharam no período, porém os migrantes ganharam mais. A proporção de indivíduos com pelo menos o ensino médio completo entre os migrantes era aproximadamente 2 pontos percentuais superior à dos não migrantes em 2000, diferença que aumentou para mais de 6 pontos em 2010. Logo, é normal que os migrantes ganhem mais, dado que possuem, em média, maior educação formal. 0 objetivo deste trabalho é investigar se tal diferencial é todo devido a diferenças educacionais e de características observadas, ou se existem fatores não observados que levam a um aumento ou diminuição dessa diferença.

Analisando o diferencial de rendimentos entre homens e mulheres, percebemos que as mulheres, apesar de serem mais educadas, tanto em 2000 quanto em 2010, auferem rendimentos consideravelmente inferiores aos percebidos pelos homens, o que indica a possibilidade de presença de discriminação de gênero. De acordo com Soares (2000), das três fontes possíveis de discriminação (formação, inserção e definição salarial), é da terceira que as mulheres sofrem, dado que possuem melhor formação do que os homens e se inserem em ocupações ou vivem em regiões similares. Ainda segundo o autor, os negros sofrem discriminação nas duas primeiras etapas citadas. Aqui observa-se que os ganhos dos indivíduos não brancos são bem inferiores aos dos brancos, assim como o nível educacional, evidenciando uma discriminação na formação desse trabalhador. Por serem menos educados, é provável que estejam em ocupações mais precárias, como argumenta Soares (2000). A boa notícia é que houve queda, no período, do diferencial de rendimentos. Enquanto em 2000 essa diferença entre brancos e não brancos era de aproximadamente $92 \%$, em 2010 passou para cerca de $69 \%$.

Mesmo sendo evidente a seleção positiva dos migrantes, principalmente em 2010, os homens nativos recebem maiores remunerações do que as mulheres migrantes, mesmo estas tendo níveis educacionais bem superiores. Em 2000, as mulheres brancas eram as 
mais educadas, porém, em média, seus salários eram inferiores àqueles recebidos por homens brancos, homens migrantes e homens nativos, sendo superior apenas ao dos homens não brancos. As mulheres não brancas recebiam os piores salários, apesar de não pertencerem ao grupo menos escolarizado. Em 2010, os migrantes brancos passaram a ser os mais escolarizados e também a receber os maiores rendimentos. Educação formal e rendimentos melhoraram para todos os grupos, porém homens não brancos continuaram sendo os menos escolarizados e mulheres não brancas permaneceram recebendo, em média, os piores rendimentos.

Os resultados apresentados nesta seção parecem indicar a presença de discriminação tanto de gênero quanto de raça, em Minas Gerais. Pode-se perceber uma melhora entre 2000 e 2010, mas o padrão de discriminação ainda persiste. Atrelado ao fator migração, pode-se chegar a diferencias expressivos de rendimentos entre estes grupos.

TABELA 2

Rendimentos mensais do trabalho e indivíduos com pelo menos ensino médio completo, segundo grupos da amostra utilizada

Estado de Minas Gerais - 2000-2010

\begin{tabular}{|c|c|c|c|c|}
\hline \multirow[b]{2}{*}{ Grupos } & \multicolumn{2}{|c|}{2000} & \multicolumn{2}{|c|}{2010} \\
\hline & $\begin{array}{l}\text { Rendimento } \\
\text { mensal do } \\
\text { trabalho (em } \\
\text { reais de julho de } \\
\text { 2010) }\end{array}$ & $\begin{array}{l}\text { Indivíduos com } \\
\text { pelo menos } \\
\text { ensino médio } \\
\text { completo } \\
(\%)\end{array}$ & $\begin{array}{c}\text { Rendimento } \\
\text { mensal do } \\
\text { trabalho } \\
\text { (em reais } \\
\text { de julho de 2010) }\end{array}$ & $\begin{array}{l}\text { Indivíduos com } \\
\text { pelo menos } \\
\text { ensino médio } \\
\text { completo } \\
(\%)\end{array}$ \\
\hline Migrantes & $1.020,08$ & 29,58 & $1.635,04$ & 47,42 \\
\hline Nativos & 927,11 & 27,49 & $1.292,72$ & 40,91 \\
\hline Homens & $1.072,73$ & 21,75 & $1.511,69$ & 35,32 \\
\hline Mulheres & 703,60 & 37,86 & $1.047,70$ & 49,91 \\
\hline Brancos & $1.191,75$ & 35,20 & $1.672,08$ & 50,07 \\
\hline Não brancos & 619,36 & 18,38 & 991,88 & 33,43 \\
\hline Homens migrantes & $1.195,82$ & 25,31 & $1.873,34$ & 42,83 \\
\hline Homens nativos & $1.058,68$ & 21,35 & $1.480,24$ & 34,66 \\
\hline Mulheres migrantes & 701,73 & 37,31 & $1.230,70$ & 55,20 \\
\hline Mulheres nativas & 703,80 & 37,91 & $1.034,80$ & 49,55 \\
\hline Homens brancos & $1.383,43$ & 28,17 & $1.942,07$ & 43,36 \\
\hline Homens não brancos & 701,74 & 14,08 & $1.132,94$ & 28,23 \\
\hline Mulheres brancas & 879,41 & 46,65 & $1.315,95$ & 58,91 \\
\hline Mulheres não brancas & 469,99 & 26,18 & 784,16 & 41,08 \\
\hline Migrantes brancos & $1.296,52$ & 38,60 & $2.152,07$ & 59,35 \\
\hline Migrantes não brancos & 682,05 & 18,55 & $1.169,30$ & 36,67 \\
\hline Nativos brancos & $1.180,16$ & 34,82 & $1.634,16$ & 49,33 \\
\hline Nativos não brancos & 612,31 & 18,36 & 977,52 & 33,17 \\
\hline
\end{tabular}

Fonte: IBGE. Censo Demográfico 2000 e 2010. Elaboração dos autores.

Apesar dos indícios de discriminação encontrados na Tabela 2, para uma maior clareza do padrão apresentado é preciso analisar também os padrões de ocupação de diferentes grupos. Na Tabela 3 são apresentadas as ocupações para migrantes, não migrantes, homens, mulheres, brancos e não brancos. Além disso, na última coluna consta a renda média 
de cada grupo ocupacional. Percebe-se o que o rendimento médio do trabalho cresceu para todos os grupos, com exceção dos empregadores.

Com relação aos migrantes e não migrantes, não se observam diferenças muito expressivas. Percebe-se que, em 2000, o percentual de trabalhadores domésticos era menor para os migrantes $(8,89 \%)$ do que para os nativos $(11,50 \%)$, situação que se inverteu em 2010 (8,93\% e 7,77\%, respectivamente). Porém, em ambos os períodos, a proporção de empregadores e conta-próprias, que são os trabalhadores mais bem remunerados em média, era mais elevada para os migrantes do que para os não migrantes: $26,5 \%$ e $21,05 \%$ em 2000 e $27,87 \%$ e $22,82 \%$ em 2010 , respectivamente.

TABELA 3

Distribuição da amostra utilizada, por condição de migração, gênero e cor, e rendimento médio do trabalho, segundo posição na ocupação

Estado de Minas Gerais - 2000-2010

Em porcentagem

\begin{tabular}{|c|c|c|c|c|c|c|c|}
\hline Posição na ocupação & Migrante & Nativo & Homem & Mulher & $\begin{array}{c}\text { Não } \\
\text { branco }\end{array}$ & Branco & $\begin{array}{l}\text { Rendimento } \\
\text { médio do trabalho } \\
\text { (em reais de julho } \\
\text { de 2010) }\end{array}$ \\
\hline \multicolumn{8}{|l|}{2000} \\
\hline $\begin{array}{l}\text { Trabalhador doméstico com } \\
\text { carteira de trabalho assinada }\end{array}$ & 3,05 & 4,48 & 0,48 & 7,82 & 4,34 & 2,27 & 344,29 \\
\hline $\begin{array}{l}\text { Trabalhador doméstico sem } \\
\text { carteira de trabalho assinada }\end{array}$ & 5,84 & 7,02 & 0,46 & 15,36 & 7,96 & 4,35 & 225,77 \\
\hline $\begin{array}{l}\text { Empregado com carteira de } \\
\text { trabalho assinada }\end{array}$ & 36,18 & 39,2 & 39,05 & 32,1 & 36,68 & 36,33 & 869,19 \\
\hline $\begin{array}{l}\text { Empregado sem carteira de } \\
\text { trabalho assinada }\end{array}$ & 28,42 & 28,24 & 29,26 & 26,94 & 30,19 & 26,96 & 685,61 \\
\hline Empregador & 3,36 & 2,64 & 3,93 & 2,2 & 1,34 & 4,86 & $4.692,21$ \\
\hline Conta-própria & 23,14 & 18,41 & 26,82 & 15,58 & 19,49 & 25,23 & $1.083,91$ \\
\hline Total & 100,00 & 100,00 & 100,00 & 100,00 & 100,00 & 100,00 & 936,44 \\
\hline \multicolumn{8}{|l|}{2010} \\
\hline $\begin{array}{l}\text { Trabalhador doméstico com } \\
\text { carteira de trabalho assinada }\end{array}$ & 3,86 & 3,22 & 0,41 & 8,93 & 4,78 & 2,73 & 591,99 \\
\hline $\begin{array}{l}\text { Trabalhador doméstico sem } \\
\text { carteira de trabalho assinada }\end{array}$ & 5,07 & 4,5 & 0,41 & 12 & 6,28 & 3,65 & 392,07 \\
\hline $\begin{array}{l}\text { Empregado com carteira de } \\
\text { trabalho assinada }\end{array}$ & 48,27 & 53,47 & 51,45 & 44,44 & 49,42 & 47,81 & $1.244,79$ \\
\hline $\begin{array}{l}\text { Empregado sem carteira de } \\
\text { trabalho assinada }\end{array}$ & 14,93 & 15,98 & 16,7 & 12,45 & 16,62 & 13,22 & 799,43 \\
\hline Empregador & 2,65 & 2,46 & 2,99 & 2,1 & 1,3 & 4,11 & $4.592,04$ \\
\hline Conta-própria & 25,22 & 20,36 & 28,03 & 20,08 & 21,59 & 28,48 & $1.469,57$ \\
\hline Total & 100,00 & 100,00 & 100,00 & 100,00 & 100,00 & 100,00 & $1.254,29$ \\
\hline
\end{tabular}

Fonte: IBGE. Censo Demográfico 2000 e 2010. Elaboração dos autores.

Em se tratando das diferenças de gênero, as discrepâncias são mais acentuadas. Enquanto o percentual de trabalhadores domésticos entre as mulheres superou os $20 \%$, em ambos os anos, entre os homens ficou em torno de $1 \%$. No extremo oposto, entre as mulheres, 20,83\% eram empregadoras ou trabalhavam por conta-própria em 2000 e $21,19 \%$ em 2010 , percentuais que, para os homens, correspondiam a 30,75\% e $31,02 \%$, 
nesse mesmo período. Tais diferenças podem ajudar a explicar os motivos pelos quais os diferencias ainda persistem.

Com relação à cor, os padrões são similares aos observados para a comparação entre homens e mulheres, sendo também importantes para explicar os diferencias de ganhos entre os grupos de brancos e não brancos.

Por fim, dada a hipótese de seletividade positiva dos migrantes, pode-se cogitar que cidades de maior porte atraiam maiores contingentes de migrantes dadas as maiores oportunidades para pessoas qualificadas. Entretanto, como pode ser visto na Tabela 4, o padrão de distribuição de migrantes e nativos é similar em cidades de diferentes tamanhos, principalmente em 2010. Para efeitos de comparação e modelagem, a mesma especificação é aplicada em ambos os anos e, por isso, não é incluído controle por tamanho de cidades nas estimativas, sendo considerado como características regional apenas se vive ou não em área urbana.

TABELA 4

Distribuição de migrantes e nativos, segundo tamanho dos municípios Estado de Minas Gerais - 2000-2010

\begin{tabular}{lccccc} 
& \multicolumn{2}{c}{$\mathbf{2 0 0 0}$} & & \multicolumn{2}{c}{$\mathbf{2 0 1 0}$} \\
\cline { 2 - 3 } \cline { 5 - 6 } Número de habitantes com renda domiciliar positiva & Nativos & Migrantes & & Nativos & Migrantes \\
\hline Até 20.000 & 90,53 & 9,47 & & 92,12 & 7,88 \\
Mais de 20.000 a 100.000 & 90,93 & 9,07 & & 92,54 & 7,46 \\
Mais de 100.000 a 500.000 & 87,70 & 12,30 & & 92,08 & 7,92 \\
Mais de 500.000 & 90,58 & 9,42 & & 93,88 & 6,12 \\
\hline
\end{tabular}

Fonte: IBGE. Censo Demográfico 2000 e 2010. Elaboração dos autores.

\section{Regressão quantílica}

Com relação aos resultados econométricos, primeiramente são apresentadas as regressões quantílicas para migrantes e não migrantes, em 2000 e 2010. Procura-se avaliar os determinantes dos rendimentos em cada percentil analisado, sendo escolhidos os percentis 10, 25, 50, 75 e 90 .

Como esperado, ser do sexo feminino afeta negativamente os ganhos, sejam essas mulheres migrantes ou nativas. Observa-se que homens apresentam maiores vantagens de rendimentos nos percentis superiores, o que corrobora a hipótese de glass ceiling (teto de vidro), que pode ser entendido como uma barreira que impede o acesso de mulheres em ocupações de melhores rendimentos (ALBRECHT; BJORKLUND; VROMAN, 2003). Isso vai de encontro ao que defende Soares (2010), que, como afirmado anteriormente, argumenta que a discriminação das mulheres não ocorre na inserção. Além disso, para os percentis 75 e 90 , a importância do gênero cresceu entre 2000 e 2010, sugerindo que o problema persiste no mercado de trabalho brasileiro. Percebe-se que o diferencial de rendimentos entre homens e mulheres continua elevado, tanto entre os migrantes quanto entre os não migrantes.

Machado e Mata (2005) afirmam que existem evidências de que a educação tem um maior efeito sobre os salários dos indivíduos no topo da distribuição salarial, e menor na 
base. Em outras palavras, de acordo com estudos empíricos, indivíduos mais educados apresentam distribuições salariais mais desiguais. Como pode ser visto nas Tabelas 5, 6, 7 e 8, essa hipótese se confirma tanto para migrantes quanto para não migrantes, em 2000 e 2010, dado que no topo da distribuição o efeito da escolaridade sobre os rendimentos é mais forte do que nos percentis inferiores.

A idade aparenta perder influência sobre os rendimentos entre 2000 e 2010, para ambos os grupos comparados, porém a remuneração cresce de acordo com a idade, como esperado, mas o efeito é mais forte nos percentis inferiores, em 2000, e nos percentis superiores, em 2010. Porém, quando a idade se torna muito elevada (efeito capitado pela variável idade2), os rendimentos decrescem, o que também era esperado. Com relação à cor, como esperado, ser de cor não branca afeta negativamente os rendimentos, tanto para migrantes quanto para não migrantes. É importante destacar que o efeito da cor sobre os rendimentos, em 2000, é bastante similar entre os diferentes percentis. Já em 2010, o efeito é menor nos percentis inferiores e maior nos superiores, sugerindo um problema de inserção dos não brancos nas ocupações de maior remuneração. Ademais, a cor é mais importante para explicar diferenciais de rendimentos entre não migrantes, em comparação aos migrantes.

Com relação à posição na ocupação, assim como em Rocha, Campos e Bittencourt (2010), os resultados mostram que o efeito negativo da não posse de carteira de trabalho assinada é mais forte nos menores percentis de renda. Inclusive, em 2000, para o percentil 90 , tanto migrantes quanto não migrantes que não possuíam carteira assinada ganhavam mais do que trabalhadores domésticos com carteira. Em 2010, em todos os percentis analisados, trabalhadores domésticos com carteira de trabalho assinada eram mais bem remunerados do que empregados sem carteira. Em 2000, o trabalhador por conta-própria apresentava rendimentos inferiores aos trabalhadores domésticos com carteira assinada, quando pertencem aos percentis mais baixos de renda (10 e 25), sendo que este padrão se inverte nos percentis mais altos. Já em 2010, o padrão favorável aos domésticos com carteira é visto até o percentil 50, depois o padrão muda. Esses dois resultados indicam uma melhoria nos rendimentos para os trabalhadores domésticos, sejam estes migrantes ou nativos.

Com relação às variáveis de residência em região metropolitana ou em área rural, observa-se que viver em área metropolitana e/ou em uma área urbana influencia positivamente os rendimentos de ambos os grupos.

Como o foco do estudo é o diferencial de rendimentos entre migrantes e não migrantes, iremos nos atentar agora para as diferenças para estes dois grupos. Em 2000, os efeitos de gênero, cor e residência em área metropolita são mais evidentes entre os não migrantes, ou seja, os coeficientes são mais elevados, enquanto os efeitos da educação formal são mais importantes para os migrantes. Em 2010, os coeficientes são mais elevados, em magnitude, em favor dos não migrantes para a variável cor e para a dummy que define se o trabalhador vive em área metropolitana. Os coeficientes da variável sexo são mais altos entre os migrantes, assim como para nível de instrução. 0 retorno maior à educação percebido pelos migrantes pode ser mais um indício da seletividade destes indivíduos. 
De maneira geral, os resultados das regressões quantílicas apresentados nesta seção mostram que as variáveis explicativas respondem de forma diferenciada, dependendo da faixa de rendimento que o indivíduo se encontra.

TABELA 5

Resultados da regressão quantílica para o grupo de migrantes Estado de Minas Gerais - 2000

\begin{tabular}{|c|c|c|c|c|c|}
\hline \multirow{2}{*}{ Variáveis } & \multicolumn{5}{|c|}{ Percentis } \\
\hline & 10 & 25 & 50 & 75 & 90 \\
\hline \multirow[t]{2}{*}{ Sexo (masculino omitido) } & $-0,325^{\star \star \star}$ & $-0,345^{\star \star \star}$ & $-0,407^{\star \star \star}$ & $-0,455^{\star \star \star}$ & $-0,454^{\star \star \star}$ \\
\hline & $(0,0071)$ & $(0,0059)$ & $(0,0051)$ & $(0,0066)$ & $(0,0096)$ \\
\hline \multirow[t]{2}{*}{ Cor (não branco omitido) } & $0,132^{\star \star \star}$ & $0,132^{\star \star \star}$ & $0,136^{\star \star \star}$ & $0,136^{\star \star \star}$ & $0,151^{\star \star \star}$ \\
\hline & $(0,0061)$ & $(0,0051)$ & $(0,0044)$ & $(0,0056)$ & $(0,0082)$ \\
\hline \multicolumn{6}{|l|}{$\begin{array}{l}\text { Nível de instrução (sem instrução e } \\
\text { fundamental incompleto omitido) }\end{array}$} \\
\hline \multirow[t]{2}{*}{ Fundamental completo e médio incompleto } & $0,238^{\star \star \star}$ & $0,239^{\star \star \star}$ & $0,254^{\star \star \star}$ & $0,312^{\star \star \star}$ & $0,363^{\star \star \star}$ \\
\hline & $(0,0083)$ & $(0,0070)$ & $(0,0061)$ & $(0,0079)$ & $(0,0117)$ \\
\hline \multirow[t]{2}{*}{ Médio completo e superior incompleto } & $0,474^{\star \star \star}$ & $0,517^{\star \star \star}$ & $0,642^{\star \star \star}$ & $0,822^{\star \star \star}$ & $0,919^{\star \star \star}$ \\
\hline & $(0,0082)$ & $(0,0069)$ & $(0,0060)$ & $(0,0078)$ & $(0,0115)$ \\
\hline \multirow[t]{2}{*}{ Superior completo } & $0,918^{\star \star \star}$ & $1,255^{\star \star \star}$ & $1,561^{\star \star \star}$ & $1,779^{\star \star \star}$ & $1,870^{\star \star \star}$ \\
\hline & $(0,0123)$ & $(0,0101)$ & $(0,0086)$ & $(0,0111)$ & $(0,0162)$ \\
\hline \multirow[t]{2}{*}{ Idade } & $0,074^{\star \star \star}$ & $0,062^{\star \star \star}$ & $0,059^{\star \star \star}$ & $0,061^{\star \star \star}$ & $0,062^{\star \star \star}$ \\
\hline & $(0,0013)$ & $(0,0011)$ & $(0,0010)$ & $(0,0014)$ & $(0,0025)$ \\
\hline \multirow{2}{*}{ Idade ao quadrado } & $-0,001^{\star \star \star}$ & $-0,001^{\star \star \star}$ & $-0,001^{\star \star \star}$ & $-0,001^{\star \star \star}$ & $-0,001^{\star * \star}$ \\
\hline & $(0,0000)$ & $(0,0000)$ & $(0,0000)$ & $(0,0000)$ & $(0,0000)$ \\
\hline \multicolumn{6}{|l|}{$\begin{array}{l}\text { Vive em companhia de cônjuge? (sim } \\
\text { omitido) }\end{array}$} \\
\hline \multirow[t]{2}{*}{ Não, mas viveu } & $-0,090 * \star \star$ & $-0,056^{\star \star \star}$ & $-0,069^{\star \star \star}$ & $-0,088^{\star \star \star}$ & $-0,079^{\star \star \star}$ \\
\hline & $(0,0099)$ & $(0,0083)$ & $(0,0072)$ & $(0,0091)$ & $(0,0134)$ \\
\hline \multirow[t]{2}{*}{ Nunca viveu } & $-0,122^{\star \star \star}$ & $-0,139^{\star \star \star}$ & $-0,165^{\star \star \star}$ & $-0,166^{\star \star \star}$ & $-0,169^{\star \star \star}$ \\
\hline & $(0,0077)$ & $(0,0066)$ & $(0,0059)$ & $(0,0076)$ & $(0,0114)$ \\
\hline \multicolumn{6}{|l|}{$\begin{array}{l}\text { Posição na ocupação (trabalhador doméstico } \\
\text { com carteira omitido) }\end{array}$} \\
\hline \multirow[t]{2}{*}{ Trabalhador doméstico sem carteira } & $-0,701^{\star \star \star}$ & $-0,473^{\star \star \star}$ & $-0,319^{\star \star \star}$ & $-0,282^{\star \star \star}$ & $-0,232^{\star \star \star}$ \\
\hline & $(0,0178)$ & $(0,0150)$ & $(0,0132)$ & $(0,0169)$ & $(0,0248)$ \\
\hline \multirow[t]{2}{*}{ Empregado com carteira assinada } & 0,020 & $0,080^{\star \star *}$ & $0,109^{\star \star \star}$ & $0,113^{\star \star \star}$ & $0,172^{\star \star \star}$ \\
\hline & $(0,0161)$ & $(0,0134)$ & $(0,0115)$ & $(0,0145)$ & $(0,0210)$ \\
\hline \multirow[t]{2}{*}{ Empregado sem carteira assinada } & $-0,339^{* \star \star}$ & $-0,171^{\star \star \star}$ & $-0,087^{\star \star \star}$ & $-0,013$ & $0,097^{\star \star \star}$ \\
\hline & $(0,0163)$ & $(0,0135)$ & $(0,0116)$ & $(0,0147)$ & $(0,0213)$ \\
\hline \multirow[t]{2}{*}{ Empregador } & $0,439^{\star \star \star}$ & $0,703^{\star \star \star}$ & $0,905^{\star \star \star}$ & $1,168^{\star \star \star}$ & $1,538^{\star \star \star}$ \\
\hline & $(0,0246)$ & $(0,0204)$ & $(0,0175)$ & $(0,0224)$ & $(0,0329)$ \\
\hline \multirow[t]{2}{*}{ Conta-própria } & $-0,377^{\star \star \star}$ & $-0,100^{\star \star \star}$ & $0,124^{\star \star \star}$ & $0,296^{\star \star \star}$ & $0,552^{\star \star \star}$ \\
\hline & $(0,0172)$ & $(0,0141)$ & $(0,0121)$ & $(0,0152)$ & $(0,0220)$ \\
\hline \multirow[t]{2}{*}{ Vive em região metropolitana? (não omitido) } & $0,139^{\star \star \star}$ & $0,143^{\star \star \star}$ & $0,137^{\star \star \star}$ & $0,120^{\star \star \star}$ & $0,112^{\star \star \star}$ \\
\hline & $(0,0064)$ & $(0,0054)$ & $(0,0047)$ & $(0,0060)$ & $(0,0088)$ \\
\hline \multirow[t]{2}{*}{ Área urbana ou rural? (urbana omitida) } & $-0,173^{\star * \star}$ & $-0,169^{\star \star \star}$ & $-0,195^{\star \star \star}$ & $-0,232^{\star \star \star}$ & $-0,255^{\star \star \star}$ \\
\hline & $(0,0078)$ & $(0,0065)$ & $(0,0057)$ & $(0,0073)$ & $(0,0107)$ \\
\hline \multirow[t]{2}{*}{ Constante } & $4,221^{\star \star \star}$ & $4,594^{\star \star \star}$ & $4,924^{\star \star \star}$ & $5,178^{\star \star \star}$ & $5,359^{\star \star \star}$ \\
\hline & $(0,0310)$ & $(0,0255)$ & $(0,0225)$ & $(0,0303)$ & $(0,0502)$ \\
\hline Observações & 83.321 & 83.321 & 83.321 & 83.321 & 83.321 \\
\hline
\end{tabular}

Fonte: Elaboração dos autores com base nos resultados das estimações.

Nota: ${ }^{\star * *} p<0,001,{ }^{* \star} p<0,01,{ }^{*} p<0,05$. Em parênteses os erros-padrão. 
TABELA 6

Resultados da regressão quantílica para o grupo de não migrantes Estado de Minas Gerais - 2000

\begin{tabular}{|c|c|c|c|c|c|}
\hline \multirow{2}{*}{ Variáveis } & \multicolumn{5}{|c|}{ Percentis } \\
\hline & 10 & 25 & 50 & 75 & 90 \\
\hline \multirow[t]{2}{*}{ Sexo (masculino omitido) } & $-0,311^{\star \star \star}$ & $-0,300^{* \star \star}$ & $-0,357^{\star \star \star}$ & $-0,396^{\star \star \star}$ & $-0,424^{\star \star \star}$ \\
\hline & $(0,0026)$ & $(0,0018)$ & $(0,0016)$ & $(0,0021)$ & $(0,0032)$ \\
\hline \multirow[t]{2}{*}{ Cor (não branco omitido) } & $0,176^{\star \star \star}$ & $0,164^{\star \star \star}$ & $0,168^{\star \star \star}$ & $0,174^{\star \star \star}$ & $0,180^{\star \star \star}$ \\
\hline & $(0,0023)$ & $(0,0016)$ & $(0,0014)$ & $(0,0018)$ & $(0,0027)$ \\
\hline \multicolumn{6}{|l|}{$\begin{array}{l}\text { Nível de instrução (sem instrução e } \\
\text { fundamental incompleto omitido) }\end{array}$} \\
\hline \multirow[t]{2}{*}{ Fundamental completo e médio incompleto } & $0,266^{\star \star \star}$ & $0,249^{\star \star \star}$ & $0,246^{\star \star \star}$ & $0,281^{\star \star \star}$ & $0,327^{\star \star \star}$ \\
\hline & $(0,0031)$ & $(0,0022)$ & $(0,0020)$ & $(0,0027)$ & $(0,0041)$ \\
\hline \multirow[t]{2}{*}{ Médio completo e superior incompleto } & $0,491^{\star \star \star}$ & $0,506^{\star \star \star}$ & $0,588^{\star \star \star}$ & $0,710^{\star \star \star}$ & $0,819^{\star \star \star}$ \\
\hline & $(0,0031)$ & $(0,0022)$ & $(0,0020)$ & $(0,0026)$ & $(0,0039)$ \\
\hline \multirow[t]{2}{*}{ Superior completo } & $0,905^{\star \star \star}$ & $1,206^{\star \star \star}$ & $1,463^{\star \star \star}$ & $1,614^{\star \star \star}$ & $1,695^{\star \star \star}$ \\
\hline & $(0,0049)$ & $(0,0034)$ & $(0,0030)$ & $(0,0039)$ & $(0,0059)$ \\
\hline \multirow[t]{2}{*}{ Idade } & $0,072^{\star \star \star}$ & $0,060^{\star \star \star}$ & $0,058^{\star \star \star}$ & $0,056^{\star \star *}$ & $0,055^{\star \star \star}$ \\
\hline & $(0,0004)$ & $(0,0003)$ & $(0,0003)$ & $(0,0004)$ & $(0,0006)$ \\
\hline \multirow[t]{2}{*}{ Idade ao quadrado } & $-0,001^{\star \star \star}$ & $-0,001^{\star \star \star}$ & $-0,001^{\star \star \star}$ & $-0,001^{* \star *}$ & $-0,001^{\star \star \star}$ \\
\hline & $(0,0000)$ & $(0,0000)$ & $(0,0000)$ & $(0,0000)$ & $(0,0000)$ \\
\hline \multicolumn{6}{|l|}{$\begin{array}{l}\text { Vive em companhia de cônjuge? (sim } \\
\text { omitido) }\end{array}$} \\
\hline \multirow[t]{2}{*}{ Não, mas viveu } & $-0,075^{\star \star \star}$ & $-0,053^{\star * *}$ & $-0,064^{\star \star \star}$ & $-0,071^{\star \star \star}$ & $-0,080^{\star \star \star}$ \\
\hline & $(0,0039)$ & $(0,0028)$ & $(0,0025)$ & $(0,0032)$ & $(0,0048)$ \\
\hline \multirow[t]{2}{*}{ Nunca viveu } & $-0,159^{\star \star \star}$ & $-0,169^{\star \star \star}$ & $-0,192^{\star \star \star}$ & $-0,202^{\star \star \star}$ & $-0,200^{\star \star \star}$ \\
\hline & $(0,0028)$ & $(0,0021)$ & $(0,0019)$ & $(0,0025)$ & $(0,0037)$ \\
\hline \multicolumn{6}{|l|}{$\begin{array}{l}\text { Posição na ocupação (trabalhador doméstico } \\
\text { com carteira omitido) }\end{array}$} \\
\hline \multirow[t]{2}{*}{ Trabalhador doméstico sem carteira } & $-0,719^{\star \star \star}$ & $-0,517^{\star \star \star}$ & $-0,341^{\star \star \star}$ & $-0,290^{\star \star \star}$ & $-0,230^{* \star \star}$ \\
\hline & $(0,0077)$ & $(0,0055)$ & $(0,0049)$ & $(0,0064)$ & $(0,0095)$ \\
\hline \multirow[t]{2}{*}{ Empregado com carteira assinada } & $0,024^{\star \star \star}$ & $0,109^{\star \star \star}$ & $0,151^{\star \star \star}$ & $0,165^{\star \star \star}$ & $0,194^{\star \star \star}$ \\
\hline & $(0,0069)$ & $(0,0049)$ & $(0,0044)$ & $(0,0056)$ & $(0,0084)$ \\
\hline \multirow[t]{2}{*}{ Empregado sem carteira assinada } & $-0,353^{\star \star \star}$ & $-0,152^{\star \star \star}$ & $-0,053^{\star \star \star}$ & $0,013^{\star}$ & $0,085^{\star \star \star}$ \\
\hline & $(0,0069)$ & $(0,0049)$ & $(0,0044)$ & $(0,0056)$ & $(0,0084)$ \\
\hline \multirow[t]{2}{*}{ Empregador } & $0,499^{\star \star \star}$ & $0,810^{\star \star \star}$ & $1,070^{\star \star \star}$ & $1,326^{\star \star \star}$ & $1,712^{\star \star \star}$ \\
\hline & $(0,0094)$ & $(0,0066)$ & $(0,0059)$ & $(0,0076)$ & $(0,0113)$ \\
\hline \multirow[t]{2}{*}{ Conta-própria } & $-0,424^{\star \star \star}$ & $-0,118^{\star \star \star}$ & $0,122^{\star \star \star}$ & $0,314^{\star \star \star}$ & $0,549^{\star \star *}$ \\
\hline & $(0,0072)$ & $(0,0050)$ & $(0,0045)$ & $(0,0057)$ & $(0,0085)$ \\
\hline \multirow[t]{2}{*}{ Vive em região metropolitana? (não omitido) } & $0,187^{\star \star \star}$ & $0,200^{\star \star \star}$ & $0,209^{\star \star \star}$ & $0,222^{\star \star \star}$ & $0,227^{\star \star \star}$ \\
\hline & $(0,0026)$ & $(0,0018)$ & $(0,0016)$ & $(0,0021)$ & $(0,0031)$ \\
\hline \multirow[t]{2}{*}{ Área urbana ou rural? (urbana omitida) } & $-0,291^{\star \star \star}$ & $-0,249^{\star \star \star}$ & $-0,248^{\star \star \star}$ & $-0,225^{\star \star \star}$ & $-0,180^{\star \star \star}$ \\
\hline & $(0,0028)$ & $(0,0020)$ & $(0,0018)$ & $(0,0023)$ & $(0,0034)$ \\
\hline \multirow[t]{2}{*}{ Constante } & $4,116^{\star \star \star}$ & $4,487^{\star \star \star}$ & $4,781^{\star \star \star}$ & $5,074^{\star \star \star}$ & $5,316^{\star \star \star}$ \\
\hline & $(0,0117)$ & $(0,0082)$ & $(0,0074)$ & $(0,0098)$ & $(0,0154)$ \\
\hline Observações & 759.209 & 759.209 & 759.209 & 759.209 & 759.209 \\
\hline
\end{tabular}

Fonte: Elaboração dos autores com base nos resultados das estimações.

Nota: ${ }^{* \star} p<0,01,{ }^{* *} p<0,05,{ }^{*} p<0,1$. Em parênteses os erros-padrão. 
TABELA 7

Resultados da regressão quantílica para o grupo de migrantes Estado de Minas Gerais - 2010

\begin{tabular}{|c|c|c|c|c|c|}
\hline \multirow{2}{*}{ Variáveis } & \multicolumn{5}{|c|}{ Percentis } \\
\hline & 10 & 25 & 50 & 75 & 90 \\
\hline \multirow[t]{2}{*}{ Sexo (masculino omitido) } & $-0,316^{\star \star \star}$ & $-0,337^{\star \star \star}$ & $-0,420^{\star \star \star}$ & $-0,502^{\star \star \star}$ & $-0,535^{\star \star \star}$ \\
\hline & $(0,0129)$ & $(0,0073)$ & $(0,0061)$ & $(0,0082)$ & $(0,0123)$ \\
\hline \multirow[t]{2}{*}{ Cor (não branco omitido) } & $0,070^{\star \star \star}$ & $0,080^{\star \star \star}$ & 0,099 *** & $0,127^{\star \star \star}$ & $0,148^{\star \star \star}$ \\
\hline & $(0,0072)$ & $(0,0046)$ & $(0,0050)$ & $(0,0072)$ & $(0,0104)$ \\
\hline \multicolumn{6}{|l|}{$\begin{array}{l}\text { Nível de instrução (sem instrução e } \\
\text { fundamental incompleto omitido) }\end{array}$} \\
\hline \multirow[t]{2}{*}{ Fundamental completo e médio incompleto } & $0,087^{\star \star \star}$ & $0,132^{\star \star \star}$ & $0,143^{\star \star *}$ & $0,184^{\star \star \star}$ & $0,233^{\star \star *}$ \\
\hline & $(0,0091)$ & $(0,0078)$ & $(0,0065)$ & $(0,0086)$ & $(0,0148)$ \\
\hline \multirow[t]{2}{*}{ Médio completo e superior incompleto } & $0,248^{\star \star \star}$ & $0,256^{\star \star \star}$ & $0,341^{\star \star \star}$ & $0,482^{\star \star \star}$ & $0,603^{* \star *}$ \\
\hline & $(0,0114)$ & $(0,0076)$ & $(0,0062)$ & $(0,0101)$ & $(0,0143)$ \\
\hline \multirow[t]{2}{*}{ Superior completo } & $0,717^{\star \star \star}$ & $0,914^{\star \star \star}$ & $1,214^{\star \star \star}$ & $1,454^{\star \star \star}$ & $1,618^{\star \star \star}$ \\
\hline & $(0,0144)$ & $(0,0135)$ & $(0,0156)$ & $(0,0143)$ & $(0,0191)$ \\
\hline \multirow[t]{2}{*}{ Idade } & $0,032^{\star \star \star}$ & $0,028^{\star \star \star}$ & $0,034^{\star \star \star}$ & $0,039^{\star \star \star}$ & $0,042^{\star \star \star}$ \\
\hline & $(0,0036)$ & $(0,0026)$ & $(0,0020)$ & $(0,0028)$ & $(0,0044)$ \\
\hline \multirow[t]{2}{*}{ Idade ao quadrado } & $-0,000^{\star \star \star}$ & $-0,000^{\star \star \star}$ & $-0,000^{\star \star \star}$ & $-0,000^{\star \star \star}$ & $-0,000^{\star \star \star}$ \\
\hline & $(0,0000)$ & $(0,0000)$ & $(0,0000)$ & $(0,0000)$ & $(0,0001)$ \\
\hline \multicolumn{6}{|l|}{$\begin{array}{l}\text { Vive em companhia de cônjuge? } \\
\text { (sim omitido) }\end{array}$} \\
\hline \multirow[t]{2}{*}{ Não, mas viveu } & 0,010 & $0,026^{\star \star \star}$ & 0,010 & $-0,021^{\star}$ & $-0,021$ \\
\hline & $(0,0066)$ & $(0,0076)$ & $(0,0064)$ & $(0,0091)$ & $(0,0144)$ \\
\hline \multirow[t]{2}{*}{ Nunca viveu } & $-0,063^{\star \star \star}$ & $-0,060^{\star \star *}$ & $-0,080^{\star \star \star}$ & $-0,102^{\star \star \star}$ & $-0,115^{\star \star \star}$ \\
\hline & $(0,0096)$ & $(0,0064)$ & $(0,0070)$ & $(0,0097)$ & $(0,0124)$ \\
\hline \multicolumn{6}{|l|}{$\begin{array}{l}\text { Posição na ocupação (trabalhador } \\
\text { doméstico com carteira omitido) }\end{array}$} \\
\hline \multirow{2}{*}{ Trabalhador doméstico sem carteira } & $-1,176^{\star \star \star}$ & $-0,798^{\star \star \star}$ & $-0,490^{\star \star \star}$ & $-0,252^{\star \star \star}$ & $-0,255^{\star \star \star}$ \\
\hline & $(0,0319)$ & $(0,0181)$ & $(0,0174)$ & $(0,0192)$ & $(0,0240)$ \\
\hline \multirow[t]{2}{*}{ Empregado com carteira assinada } & 0,018 & $-0,007$ & $0,058^{\star \star \star}$ & $0,139^{\star \star \star}$ & $0,190^{\star \star \star}$ \\
\hline & $(0,0173)$ & $(0,0092)$ & $(0,0111)$ & $(0,0150)$ & $(0,0219)$ \\
\hline \multirow[t]{2}{*}{ Empregado sem carteira assinada } & $-0,582^{\star \star \star}$ & $-0,305^{\star \star \star}$ & $-0,213^{\star \star \star}$ & $-0,100^{\star \star \star}$ & $-0,011$ \\
\hline & $(0,0230)$ & $(0,0144)$ & $(0,0120)$ & $(0,0145)$ & $(0,0211)$ \\
\hline \multirow[t]{2}{*}{ Empregador } & $0,139 *$ & $0,481^{\star \star \star}$ & $0,691^{\star \star \star}$ & $0,943^{\star \star \star}$ & $1,250 * \star \star$ \\
\hline & $(0,0626)$ & $(0,0314)$ & $(0,0300)$ & $(0,0471)$ & $(0,0615)$ \\
\hline \multirow[t]{2}{*}{ Conta-própria } & $-0,570^{\star \star \star}$ & $-0,224^{\star \star \star}$ & $-0,030^{\star}$ & $0,193^{\star \star *}$ & $0,425^{\star \star \star}$ \\
\hline & $(0,0231)$ & $(0,0123)$ & $(0,0133)$ & $(0,0203)$ & $(0,0253)$ \\
\hline \multirow[t]{2}{*}{ Vive em região metropolitana? (não omitido) } & $0,053^{\star \star \star}$ & $0,080^{\star \star \star}$ & $0,080^{\star \star \star}$ & $0,099^{\star \star *}$ & $0,102^{\star \star \star}$ \\
\hline & $(0,0069)$ & $(0,0058)$ & $(0,0058)$ & $(0,0087)$ & $(0,0117)$ \\
\hline \multirow[t]{2}{*}{ Área urbana ou rural? (urbana omitida) } & $-0,111^{\star \star \star}$ & $-0,140^{\star \star \star}$ & $-0,152^{\star \star \star}$ & $-0,189 * * \star$ & $-0,239 * \star \star$ \\
\hline & $(0,0121)$ & $(0,0068)$ & $(0,0067)$ & $(0,0079)$ & $(0,0114)$ \\
\hline \multirow[t]{2}{*}{ Constante } & $5,549^{\star \star \star}$ & $5,784^{\star \star \star}$ & $5,838^{\star \star \star}$ & $5,915^{\star \star \star}$ & $6,053^{\star \star \star}$ \\
\hline & $(0,0721)$ & $(0,0521)$ & $(0,0419)$ & $(0,0579)$ & $(0,0829)$ \\
\hline Observações & 57.808 & 57.808 & 57.808 & 57.808 & 57.808 \\
\hline
\end{tabular}

Fonte: Elaboração dos autores com base nos resultados das estimações.

Nota: ${ }^{\star \star \star} p<0,01,{ }^{\star \star} p<0,05,{ }^{\star} p<0,1$. Em parênteses os erros-padrão. 
TABELA 8

Resultados da regressão quantílica para o grupo de não migrantes Estado de Minas Gerais - 2010

\begin{tabular}{|c|c|c|c|c|c|}
\hline \multirow{2}{*}{ Variáveis } & \multicolumn{5}{|c|}{ Percentis } \\
\hline & 10 & 25 & 50 & 75 & 90 \\
\hline \multirow[t]{2}{*}{ Sexo (masculino omitido) } & $-0,299^{\star \star \star}$ & $-0,302^{\star \star \star}$ & $-0,337^{\star \star \star}$ & $-0,413^{\star \star \star}$ & $-0,468^{\star \star \star}$ \\
\hline & $(0,0008)$ & $(0,0013)$ & $(0,0012)$ & $(0,0016)$ & $(0,0031)$ \\
\hline \multirow[t]{2}{*}{ Cor (não branco omitido) } & $0,104^{\star \star \star}$ & $0,121^{\star \star \star}$ & $0,114^{\star \star \star}$ & $0,147^{\star \star \star}$ & $0,172^{\star \star \star}$ \\
\hline & $(0,0007)$ & $(0,0012)$ & $(0,0010)$ & $(0,0014)$ & $(0,0027)$ \\
\hline \multicolumn{6}{|l|}{$\begin{array}{l}\text { Nivel de instrução (sem instrução e } \\
\text { fundamental incompleto omitido) }\end{array}$} \\
\hline \multirow[t]{2}{*}{ Fundamental completo e médio incompleto } & $0,158^{\star \star \star}$ & $0,148^{\star \star \star}$ & $0,173^{\star \star \star}$ & $0,213^{\star \star \star}$ & $0,249^{\star * *}$ \\
\hline & $(0,0009)$ & $(0,0016)$ & $(0,0015)$ & $(0,0021)$ & $(0,0040)$ \\
\hline \multirow[t]{2}{*}{ Médio completo e superior incompleto } & $0,279^{\star \star \star}$ & $0,266^{\star \star \star}$ & $0,325^{\star \star \star}$ & $0,435^{\star \star \star}$ & $0,535^{\star \star \star}$ \\
\hline & $(0,0009)$ & $(0,0015)$ & $(0,0014)$ & $(0,0019)$ & $(0,0038)$ \\
\hline \multirow[t]{2}{*}{ Superior completo } & $0,653^{\star \star \star}$ & $0,785^{\star \star \star}$ & $1,046^{\star \star \star}$ & $1,299^{\star \star \star}$ & $1,474^{\star \star \star}$ \\
\hline & $(0,0013)$ & $(0,0022)$ & $(0,0020)$ & $(0,0028)$ & $(0,0054)$ \\
\hline \multirow[t]{2}{*}{ Idade } & $0,023^{\star \star *}$ & $0,022^{\star \star \star}$ & $0,028^{\star \star \star}$ & $0,033^{\star \star \star}$ & $0,037^{\star \star \star}$ \\
\hline & $(0,0003)$ & $(0,0004)$ & $(0,0004)$ & $(0,0006)$ & $(0,0011)$ \\
\hline \multirow[t]{2}{*}{ Idade ao quadrado } & $-0,000^{\star \star \star}$ & $-0,000^{\star \star \star}$ & $-0,000^{\star \star \star}$ & $-0,000^{\star \star \star}$ & $-0,000^{\star \star \star}$ \\
\hline & $(0,0000)$ & $(0,0000)$ & $(0,0000)$ & $(0,0000)$ & $(0,0000)$ \\
\hline \multicolumn{6}{|l|}{ Vive em companhia de cônjuge? (sim omitido) } \\
\hline \multirow[t]{2}{*}{ Não, mas viveu } & $-0,016^{\star \star \star}$ & $-0,015^{\star \star \star}$ & $-0,027^{\star \star \star}$ & $-0,036^{\star \star \star}$ & $-0,044^{\star \star \star}$ \\
\hline & $(0,0010)$ & $(0,0017)$ & $(0,0015)$ & $(0,0021)$ & $(0,0040)$ \\
\hline \multirow[t]{2}{*}{ Nunca viveu } & $-0,120 * \star \star$ & $-0,108^{\star \star \star}$ & $-0,128^{\star \star \star}$ & $-0,169^{\star \star \star}$ & $-0,182^{\star \star \star}$ \\
\hline & $(0,0009)$ & $(0,0015)$ & $(0,0014)$ & $(0,0019)$ & $(0,0037)$ \\
\hline \multicolumn{6}{|l|}{$\begin{array}{l}\text { Posição na ocupação (trabalhador doméstico } \\
\text { com carteira omitido) }\end{array}$} \\
\hline \multirow[t]{2}{*}{ Trabalhador doméstico sem carteira } & $-1,198^{\star \star \star}$ & $-0,843^{\star \star \star}$ & $-0,521^{\star \star \star}$ & $-0,250^{\star \star \star}$ & $-0,224^{* \star *}$ \\
\hline & $(0,0023)$ & $(0,0039)$ & $(0,0035)$ & $(0,0048)$ & $(0,0092)$ \\
\hline \multirow[t]{2}{*}{ Empregado com carteira assinada } & $-0,001$ & $-0,024^{\star \star \star}$ & $0,049^{\star \star \star}$ & $0,105^{\star \star \star}$ & $0,145^{\star \star \star}$ \\
\hline & $(0,0019)$ & $(0,0033)$ & $(0,0030)$ & $(0,0041)$ & $(0,0078)$ \\
\hline \multirow[t]{2}{*}{ Empregado sem carteira assinada } & $-0,621^{\star \star \star}$ & $-0,344^{\star \star \star}$ & $-0,195^{\star \star \star}$ & $-0,108^{\star \star \star}$ & $-0,044^{\star \star \star}$ \\
\hline & $(0,0020)$ & $(0,0034)$ & $(0,0031)$ & $(0,0043)$ & $(0,0082)$ \\
\hline \multirow[t]{2}{*}{ Empregador } & $0,266^{\star \star \star}$ & $0,492^{\star \star \star}$ & $0,798^{\star \star \star}$ & $1,052^{\star \star \star}$ & $1,333^{\star \star \star}$ \\
\hline & $(0,0029)$ & $(0,0050)$ & $(0,0045)$ & $(0,0061)$ & $(0,0118)$ \\
\hline \multirow[t]{2}{*}{ Conta-própria } & $-0,555^{\star \star \star}$ & $-0,230^{\star \star \star}$ & $-0,022^{\star \star \star}$ & $0,213^{\star \star \star}$ & $0,430 * \star \star$ \\
\hline & $(0,0020)$ & $(0,0034)$ & $(0,0031)$ & $(0,0042)$ & $(0,0080)$ \\
\hline \multirow[t]{2}{*}{ Vive em região metropolitana? (não omitido) } & $0,120 * \star \star$ & $0,138^{\star \star *}$ & $0,150^{\star \star \star}$ & $0,184^{\star \star \star}$ & $0,209^{\star * \star}$ \\
\hline & $(0,0008)$ & $(0,0014)$ & $(0,0013)$ & $(0,0017)$ & $(0,0033)$ \\
\hline \multirow[t]{2}{*}{ Área urbana ou rural? (urbana omitida) } & $-0,300^{\star \star \star}$ & $-0,235^{\star \star \star}$ & $-0,209^{\star \star \star}$ & $-0,206^{\star \star \star}$ & $-0,198^{\star \star \star}$ \\
\hline & $(0,0009)$ & $(0,0015)$ & $(0,0014)$ & $(0,0019)$ & $(0,0037)$ \\
\hline \multirow[t]{2}{*}{ Constante } & $5,631^{\star \star \star}$ & $5,812^{\star \star \star}$ & $5,820 * \star \star$ & $5,885^{\star \star \star}$ & $6,006^{\star \star \star}$ \\
\hline & $(0,0058)$ & $(0,0100)$ & $(0,0091)$ & $(0,0124)$ & $(0,0238)$ \\
\hline Observações & 673.103 & 673.103 & 673.103 & 673.103 & 673.103 \\
\hline
\end{tabular}

Fonte: Elaboração dos autores com base nos resultados das estimações.

Nota: ${ }^{\star \star \star} p<0,01,{ }^{* \star} p<0,05,{ }^{*} p<0,1$. Em parênteses os erros-padrão. 


\section{Decomposição de Junh, Murphy e Pierce}

A decomposição de Junh, Murphy e Pierce foi realizada para os percentis 10, 25, 50, 75 e 90, pois, como já mostrado anteriormente, as variáveis de controle, em especial o nível de instrução, exercem efeito sobre os ganhos de forma diferenciada nos diferentes pontos da distribuição dos ganhos. 0 método é simples e consiste em se utilizarem as variáveis de controle (efeito quantidade), os coeficientes estimados (efeitos-preço) e os resíduos das regressões (efeitos não observáveis) para reconstruir de forma sequencial a distribuição de rendimentos (ULYSSEA, 2007). Dessa forma, é possível analisar a contribuição de cada elemento mencionado ao diferencial de rendimentos.

Como pode ser visto na Tabela 9, o diferencial total é o mesmo em todos os percentis, o que varia são os componentes, tendo subido consideravelmente entre 2000 e 2010 , passando de aproximadamente 0,11 para cerca de 0,16. Em ambos os anos, quanto mais elevado o percentil, menor é a importância da parte explicada para explicar os diferenciais. Entretanto, para explicar o aumento da divergência de renda do trabalho no período, percebe-se que nos percentis mais elevados a importância da parte explicada é mais importante do que nos percentis inferiores.

Quando se analisam os termos separados da parte explicada, fica evidente que, quanto mais elevado o percentil, maior é a importância das características observáveis dos trabalhadores $(\mathrm{Q})$, mas menor é o retorno a tais características $(\mathrm{P})$. Portanto, entre os que recebem altos rendimentos, as habilidades observadas contribuíram em maior magnitude para o aumento dos diferenciais de rendimentos, enquanto o retorno a tais características contribuiu para uma queda.

Como esperado, os migrantes são positivamente selecionados com relação a ambas as características observáveis e não observáveis, as quais contribuíram para uma maior divergência de renda no período. Quando se separam os efeitos não observados em efeitos-quantidade e preço, novamente o efeito-quantidade é positivo em prol dos migrantes e o efeito-preço positivo em prol dos nativos.

A única exceção aos resultados mencionados ocorre no percentil 90. Nesse caso, a parte não explicada é negativa. Porém, não é indicação de que os migrantes passaram a ser negativamente selecionados com relação às habilidades não observadas. Quando se observa a parte não explicada separadamente, percebe-se que o efeito-preço é responsável por tal efeito. Em outras palavras, os migrantes apresentam melhores habilidades não observadas $(\mathrm{Q})$, mas a remuneração a estas características é inferior à dos nativos. Isso ocorre em todos os percentis, o que pode sugerir discriminação contra os migrantes, porém, apenas no percentil 90 este efeito é maior do que o efeito quantidade.

Os resultados mostram que a questão da seletividade com relação às características observáveis e não observáveis entre os migrantes não apenas está presente no mercado de trabalho mineiro, como também cresceu de importância no período. Portanto, a principal lição que se pode tirar destes resultados é que são dois os fatores principais que 
levam os migrantes a serem mais bem remunerados em Minas Gerais: possuem melhores características observáveis e não observáveis que os nativos.

TABELA 9

Decomposição de Juhn-Murphy-Pierce

\begin{tabular}{|c|c|c|c|c|c|}
\hline \multirow{2}{*}{ Variáveis } & \multicolumn{5}{|c|}{ Percentis } \\
\hline & 10 & 25 & 50 & 75 & 90 \\
\hline Diferencial migrante-nativo 2000 & 0,10895 & 0,10895 & 0,10895 & 0,10895 & 0,10895 \\
\hline Diferencial migrante-nativo 2010 & 0,16079 & 0,16079 & 0,16079 & 0,16079 & 0,16079 \\
\hline Efeito de quantidade 2000 & 0,05964 & 0,04877 & 0,03754 & 0,02206 & $-0,00126$ \\
\hline Efeito de quantidade 2010 & 0,08238 & 0,06660 & 0,06698 & 0,06343 & 0,05197 \\
\hline Diferença residual 2000 & 0,04931 & 0,06018 & 0,07141 & 0,08689 & 0,11021 \\
\hline Diferença residual 2010 & 0,07841 & 0,09419 & 0,09381 & 0,09735 & 0,10882 \\
\hline Diferença total (MN2010 - MN2000) & 0,05184 & 0,05184 & 0,05184 & 0,05184 & 0,05184 \\
\hline Parte explicada & 0,02274 & 0,01783 & 0,02943 & 0,04138 & 0,05323 \\
\hline Parte não explicada & 0,02910 & 0,03402 & 0,02241 & 0,01046 & $-0,00139$ \\
\hline \multicolumn{6}{|l|}{ Separação da parte explicada } \\
\hline Efeito quantidade (Q) & 0,03476 & 0,04306 & 0,05110 & 0,05909 & 0,06349 \\
\hline Efeito preço $(P)$ & $-0,01323$ & $-0,01855$ & $-0,01296$ & $-0,00647$ & $-0,00116$ \\
\hline Interação (QxP) & 0,00121 & $-0,00669$ & $-0,00870$ & $-0,01125$ & $-0,00910$ \\
\hline \multicolumn{6}{|l|}{ Separação da parte não explicada } \\
\hline Efeito quantidade (Q) & 0,03183 & 0,03946 & 0,02839 & 0,01696 & 0,00533 \\
\hline Efeito preço $(\mathrm{P})$ & $-0,00169$ & $-0,00332$ & $-0,00434$ & $-0,00552$ & $-0,00631$ \\
\hline Interação (QxP) & $-0,00104$ & $-0,00213$ & $-0,00165$ & $-0,00097$ & $-0,00041$ \\
\hline
\end{tabular}

Fonte: Elaboração dos autores com base nos resultados das estimações.

\section{Considerações finais}

Este artigo teve por objetivo contribuir para a análise dos determinantes dos diferenciais de rendimentos entre migrantes e não migrantes em Minas Gerais, a partir de dados dos Censos 2000 e 2010. Para tanto, utiliza-se aqui uma metodologia de análise contrafactual, a decomposição de Juhn, Murphy e Pierce (1993). De maneira geral, os exercícios realizados consistem em analisar os diferencias de rendimentos em diferentes pontos da distribuição, além de mudanças ao longo do tempo.

As decomposições mostram que as habilidades não observadas (produtividade, esforço, etc.) dos indivíduos são importantes para explicar os diferenciais de rendimentos, tendo também contribuído para o aumento de divergência no período, de forma que se não existissem as habilidades não observadas, os diferenciais seriam menores.

A principal conclusão e contribuição do trabalho é a de que a desigualdade de rendimentos entre migrantes e não migrantes, em Minas Gerais, que cresceu consideravelmente entre 2000 e 2010, tem com base dois fatores principais: os migrantes apresentam melhores características observáveis e também habilidades não observáveis. Além disso, estas características variam em importância quando observamos em qual parte da distribuição dos 
ganhos estes trabalhadores se encontram. No geral, os efeitos-quantidade (escolaridade, experiência, etc.) apresentam maior efeito nos percentis inferiores (menores rendimentos), enquanto os efeitos não observados são mais importantes nos percentis mais elevados (que apresentam rendimentos mais altos). Porém, o efeito de características observáveis cresceu em importância no período, no sentido de explicar a desigualdade de rendimentos entre migrantes e não migrantes.

Dado que o efeito-preço $(\mathrm{P})$, em relação tanto à parte explicada quanto àquela não explicada, é negativo, ou seja, o retorno às características observáveis e não observáveis é maior para os nativos, pode-se indagar se existe discriminação contra os migrantes. Entretanto, em termos de magnitude, os coeficientes são muito mais baixos do que os coeficientes para os efeitos-quantidade $(\mathrm{Q})$. Pode ser um efeito de tempo de assimilação do migrante, que pode estar, por exemplo, em ocupação distinta de sua escolaridade ou área. Porém, como o enfoque não é este, para obtenção de mais detalhes, teriam que ser empregadas outras metodologias.

Conclui-se, dessa forma, como defende grande parte da literatura, que os migrantes realmente são positivamente selecionados, porém, entre aqueles com maior educação formal, principalmente em 2010, não é possível adquirir o rendimento esperado, ou a diferença de rendimento esperada, dadas suas maiores habilidades. Seguindo as ideias de Soares (2000), é provável que os migrantes estejam ganhando menos do que deveriam nos quantis superiores ou por estarem inseridos em setores que remuneram mal ou por estarem no setor informal da economia. Por fim, devido às maiores habilidades dos migrantes, houve crescimento do diferencial entre migrantes e não migrantes, mostrando a importância que aqueles têm para o mercado de trabalho receptor.

Finalizando, destaca-se que a metodologia, apesar de adequada para o estudo, apresenta limitações, como já afirmado ao longo do texto. Machado e Mata (2005) propõem um método distinto que se baseia na estimação da função de densidade marginal dos salários em um período implicada pelas distribuições contrafactuais de alguns ou todos os atributos observados. Como exemplo, seria possível observar a densidade salarial que teria prevalecido em 2010 se a distribuição dos migrantes fosse como em 2000 e as outras covariáveis como em 2010. Com isso, é possível analisar a contribuição das mudanças na migração às mudanças observadas na distribuição salarial. Entretanto, não seria possível, por exemplo, captar alterações em características não observáveis. Portanto, a aplicação deste modelo é proposta para trabalho futuro, dada a diferença do foco de análise.

\section{Refêrencias}

ALBRECHT, J.; BJÖRKLUND, A.; VROMANIS, S. Is there a glass ceiling in Sweden? Journal of Labor Economics, v. 21, n. 1, p. 145-177, 2003.

AMARAL, E. F. L.; RIOS-NETO, E. L. G.; POTTER, J. E. The influence of internal migration on male earnings in Brazil, 1970-2000. Migration and Development, v. 5, n. 1, p. 55-78, 2016. 
AXELSSON, R.; WESTERLUND, O. A panel study of migration, self-selection and household real income. Journal of Population Economics, v. 11, n. 1, p. 113-126, 1998.

BASKER, E. Education, job search and migration. Columbia: University of Missouri, April 2003.

BATISTA, N. N. F.; CACCIAMALI, M. C. Wage differences between men and women according to condition of migration. Revista Brasileira de Estudos de População, v. 26, n. 1, p. 97-115, 2009.

BORJAS, G. Assimilation and changes in cohort quality revisited: what happened to immigrant earnings in the 1980s? Journal of Labor Economics, v. 13, n. 2, p. 201-45, 1995.

. Assimilation, changes in cohort quality, and the earnings of immigrants. Journal of Labor Economics, v. 3, n. 4, p. 463-89, 1985.

. Labor economics. 3. ed. Boston: McGraw-Hill/Irwin, 2004.

Self-selection and the earnings of immigrants. The American Economic Review, v. 77, n. 4, p. 531-553, 1987.

. The labor demand curve is downward sloping: reexamining the impact of immigration on the labor market. The Quarterly Journal of Economics, v. 118, n. 4, p. 1335-1374, 2003.

BUCHINSKY, M. Changes in the U.S. Wage structure 1963-1987: application of quantile regression. Econometrica, v. 62, n. 2, p. 405-458, 1994.

Recent advances in quantile regression models: a practical guideline for empirical research. Journal of Human Resources, v. 33, n. 1, p. 88-126, 1998.

CARD, D. Immigrant inflows, native outflows, and the local labor market impacts of higher immigration. Journal of Labor Economics, v. 19, n. 1, p. 22-64, 2001a.

. Is the new immigration really so bad? The Economic Journal, v. 115, p. 300-323, 2001b.

DELL'ARINGA, C.; LUCIFORA, C.; PAGANI, L. Earnings differentials between immigrants and natives: the role of occupational attainment. IZA Journal of Migration, v. 4, n. 1, p. 1-18, 2015.

DUSTMANN, C.; FADLON, I.; WEISS, Y. Return migration, human capital accumulation and the brain drain. Journal of Development Economics, v. 95, n. 1, p. 58-67, 2011.

FREGUGLIA, R. S. Efeitos da migração sobre os salários no Brasil. Tese (Doutorado em Teoria Econômica) - Faculdade de Economia, Administração e Contabilidade, Universidade de São Paulo, São Paulo, 2007.

GAMA, L. C. D.; MACHADO, A. F. Migração e rendimentos no Brasil: análise dos fatores associados no período intercensitário 2000-2010. Estudos Avançados, São Paulo, v. 28, n. 81, p. 155-174, 2014.

HOLST, E.; SCHÄFER, A.; SCHROOTEN, M. Gender, migration, remittances: evidence from Germany. Berlin: DIW Berlin, The German Socio-Economic Panel, 2008 (SOEP paper, n. 111).

IPEA - Instituto de Pesquisa Econômica Aplicada. Sobre a recente queda da desigualdade de renda no Brasil. Brasília: Ipea, agosto de 2006 (Nota Técnica). Disponível em: 〈http://www. ipea.gov.bry.

JUHN, C.; MURPHY, K. M.; PIERCE, B. Wage inequality and the rise in returns to skill. Journal of Political Economy, v. 101, n. 3, p. 410-41, 1993.

KOENKER, R.; BASSET, G. Regression quantiles. Econometrica, v. 46, n. 1, p. 33-50, 1978.

MACHADO, J. A. F.; MATA, J. Counterfactual decomposition of changes in wage distributions using quantile regression. Journal of Applied Econometrics, v. 20, n. 4, p. 445-465, 2005. 
PEREIRA, V. M. 0 recente processo migratório interno brasileiro e seus determinantes. $62 \mathrm{f}$. Dissertação (Mestrado) - Escola Superior de Agricultura "Luiz de Queiroz" (Esalq), Piracicaba, 2000.

ROCHA, M.; BITTENCOURT, M.; CAMPOS, M. A evolução das desigualdades por categorias de escolaridades entre 1996 e 2004: uma análise com regressões quantílicas. Revista de Economia Contemporânea, Rio de Janeiro, v. 14, n. 1, p. 141-166, jan./abr. 2010.

RODRIGUES, C. G. A relação entre a expansão do acesso ao ensino e o desempenho escolar no Brasil: evidências com base no SAEB para o período de 1997 a 2005. Tese (Doutorado) - Centro de Desenvolvimento e Planejamento Regional (Cedeplar), Universidade Federal de Minas Gerais (UFMG), Belo Horizonte, 2009.

SANTOS, C.; FERREIRA, C. F. Migração e distribuição regional de renda no Brasil. Pesquisa e Planejamento Econômico, v. 37, n. 3, p. 405-426, dez. 2007.

SASAKI, E. M.; ASSIS, G. O. Teorias das Migrações Internacionais. In: XII ENCONTRO NACIONAL DE ESTUDOS POPULACIONAIS. Anais.... Caxambu: Abep, outubro de 2000.

SJAASTAD, L. A. The costs and returns of human migration. Journal of Political Economy, v. 70, n. 5, p. 80-93, 1962.

SOARES, S. A distribuição dos rendimentos do trabalho e a queda da desigualdade de 1995 a 2009. Boletim Mercado de Trabalho - Conjuntura e Análise, n. 45, p. 35-40, 2010 (Nota Técnica). Disponivel em: 〈http://www.ipea.gov.br〉.

. 0 perfil da descriminação no mercado de trabalho - homens negros, mulheres brancas e mulheres negras. Brasília: Ipea, novembro de 2000 (Texto para discussão, n. 769).

ULYSSEA, G. Segmentação no mercado de trabalho e desigualdade de rendimentos no Brasil: uma análise empírica. Brasília: Ipea, fevereiro de 2007 (Texto para discussão, n. 1261).

YUN, M. Wage differentials, discrimination and inequality: a cautionary note on the Junh, Murphy and Pierce Decomposition method. Scottish Journal of Political Economy, v. 56, n. 1, p. 114-122, 2009.

\section{Sobre os autores}

Luiz Carlos Day Gama é doutor pelo Departamento de Economia, Centro de Desenvolvimento e Planejamento Regional (Cedeplar), da Universidade Federal de Minas Gerais (UFMG).

Ana Maria Hermeto é doutora em Demografia pelo Centro de Desenvolvimento e Planejamento Regional (Cedeplar), da Universidade Federal de Minas Gerais (UFMG). Professora associada do Cedeplar/UFMG.

\section{Endereço para correspondência}

Luiz Carlos Day Gama

Rua Venezuela, 610, ap. 603

30315-250 - Belo Horizonte-MG, Brasil

Ana Maria Hermeto

Cedeplar/Face/UFMG

Av. Antonio Carlos, 6627, Pampulha

31270-901 - Belo Horizonte-MG, Brasil 


\begin{abstract}
Income gaps between migrants and non-migrants in Minas Gerais

This paper analyzes the causes of income gaps between migrants and non-migrants in the state of Minas Gerais. Under the hypothesis that these differentials and its causes are distinct along the wage distribution, we estimate quantile regressions e, with the results, we decompose the differences by the Junh, Murphy e Pierce (JMP) method. The main results indicate that: i) there is income inequality in favor of migrants, and it got higher between 2000 and 2010; ii) as expected, differentials present different reasons in each quantile of the income distribution; iii) non-observed effects (productivity, effort, etc.) are important in explaining inequality, for both years; iv) however, to explain the raise in the income gap, both observable and non-observable characteristics are more important than the returns to such characteristics. In this way, as most of the literature attests, migrants are positively selected, but among those with higher formal education, especially in 2010 , it is not possible to acquire the expected income, or differential in income, given their greater skills.
\end{abstract}

Keywords: Migrants. Minas Gerais. Decomposition of differences. Income inequality.

\title{
Resumen
}

\section{Brechas salariales entre migrantes y no migrantes en Minas Gerais}

En este trabajo se analizan las causas de la brecha salarial entre migrantes y no migrantes en el estado de Minas Gerais. Bajo la hipótesis de que estos diferenciales y sus causas son distintos a lo largo de la distribución de salarios, estimamos las regresiones cuantílicas e, con los resultados, se descomponen las diferencias por el método de Junh, Murphy e Pierce (JMP). Los principales resultados indican que: i) hay desigualdad de salariales a favor de los migrantes, y se ha incrementado entre 2000 y 2010; ii) como se esperaba, los diferenciales presentan diferentes razones en cada cuantil de la distribución del salare; iii) los efectos no observados (productividad, esfuerzo, etc.) son importantes para explicar la desigualdad, para ambos años; iv) sin embargo, para explicar el aumento de la brecha de salares, tanto las características observables como las no observables son más importantes que las rentabilidades de tales características. De esta manera, como lo atestigua la mayoría de la literatura, los migrantes son seleccionados positivamente, pero entre los que tienen mayor educación formal, especialmente en 2010, no es posible obtener el rendimiento esperado, o diferencial esperado en los rendimientos, dadas sus mayores habilidades.

Palabras clave: Migrantes. Descomposición de diferencias. La desigualdad de salares. 